\title{
碰撞造山带海沟盆地的识别 以雅鲁藏布缝合带为例
}

\author{
胡修棉 ${ }^{*}$, 安慰 ${ }^{2}$, Eduardo GARZANTI ${ }^{3}$, 刘群 ${ }^{1}$
}

1. 南京大学大陆动力学研究院, 内生金属矿床成矿机制研究国家重点实验室, 南京大学地球科学与工程学院, 南京 210023;

2. 合肥工业大学资源与环境工程学院, 合肥 230009 ;

3. Department of Earth and Environmental Sciences, Università di Milano-Bicocca, Milano 20126, Italy

* 通讯作者, E-mail: huxm@nju.edu.cn

收稿日期：2019-10-27; 收修改稿日期：2020-10-10; 接受日期：2020-10-14; 网络版发表日期：2020-11-10

国家自然科学基金项目(批准号: 91755209、41972106)资助

\begin{abstract}
摘要海沟盆地是俯冲带重要的沉积储库, 记录了古水系和古地理信息. 长期以来造山带海沟盆地的识别一直存 在巨大挑战. 近年来在雅鲁藏布缝合带成功识别出多套海沟盆地地层. 根据时代和构造背景的差异, 这些地层可 分为两类: 一类发育于白严纪新特提斯洋俯冲阶段, 包括甲查拉组、荣马瓦组、罗岗错组; 另一类形成于古近纪 印度-亚洲大陆初始碰撞阶段, 以桑单林组-者雅组为代表. 前者发育在俯冲的特提斯洋壳上, 在大洋俯冲阶段增生 到俯冲杂岩带; 而后者不整合沉积于印度大陆北缘, 在大陆初始碰撞阶段卷入到俯冲杂岩带. 海沟盆地典型的岩 石类型包括硅质岩、硅质页岩、粉砂质和砂质浊积岩, 以出现滑塌堆积和缺乏碳酸盐岩为特征。碎屑物质主要来 自上覆板片. 本文总结了海沟盆地的基本特征和识别依据.
\end{abstract}

关键词 海沟盆地, 物源分析, 雅鲁藏布缝合带, 藏南, 白严纪-古近纪, 喜马拉雅造山带

\section{1 海沟盆地及其演化}

现今大洋的地质调查表明，海沟盆地发育于俯冲 大洋板片与上覆板块的地表结合处，通常呈弧形或线 形平行于俯冲带分布，与发育于岩浆弧与增生楔之间 的弧前盆地、俯冲增生楔之上的海沟斜坡盆地共同构 成了俯冲体系的沉积储库(Thornburg和Kulm, 1987; Dickinson，1995). 海沟盆地的水深一般超过 4000 5000m, 接近或者超过碳酸盐补偿深度(CCD面). 因此, 绝大部分的海沟盆地缺乏钙质沉积, 背景沉积以
远洋硅质岩、硅质页岩为主，周期性地发育深水重力 流沉积(图1, Underwood和Moore, 1995, 2011). 海沟多 呈两壁陡峭且狭窄的“V”形槽状洼陷，内斜坡较陡(地 形坡度一般超过 $5^{\circ}$, 有的坡度可超过 $30^{\circ}$ ). 因此, 在海 沟环境中常发育重力流, 如浊流、碎屑流、滑塌、滑 移等沉积作用(Thornburg和Kulm, 1987).

海沟深水沉积主要有两种来源(图2, 肖春晖等, 2017): 最主要的一种来自上覆板块陆源碎屑的供给, 其中包括俯冲增生楔的侵蚀，而增生楔的主要成分为 海沟下潜时被上盘刮削下来的大洋板块地层 $($ Ocean 

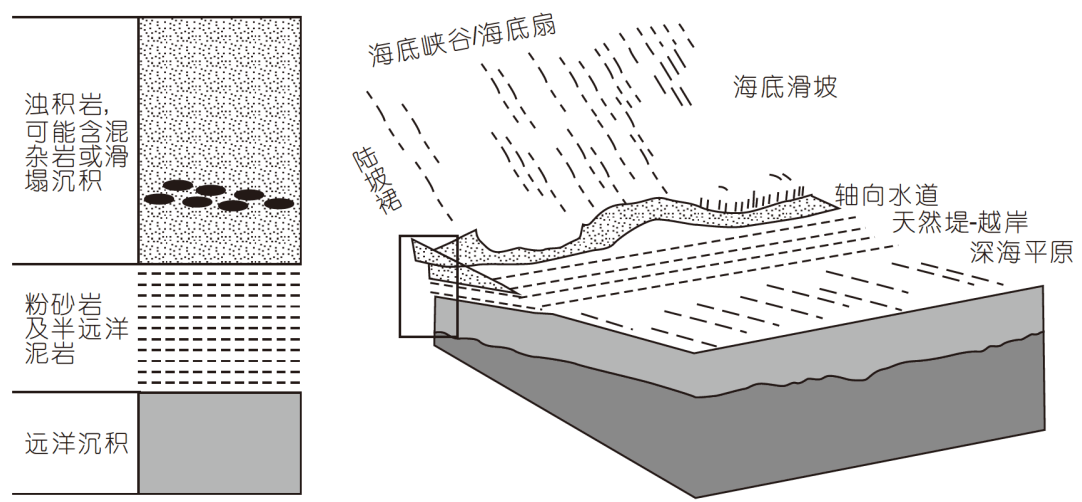

图 1 海沟盆地中主要的沉积过程及典型的向上变粗的沉积序列

修改自Underwood和Moore(1995)
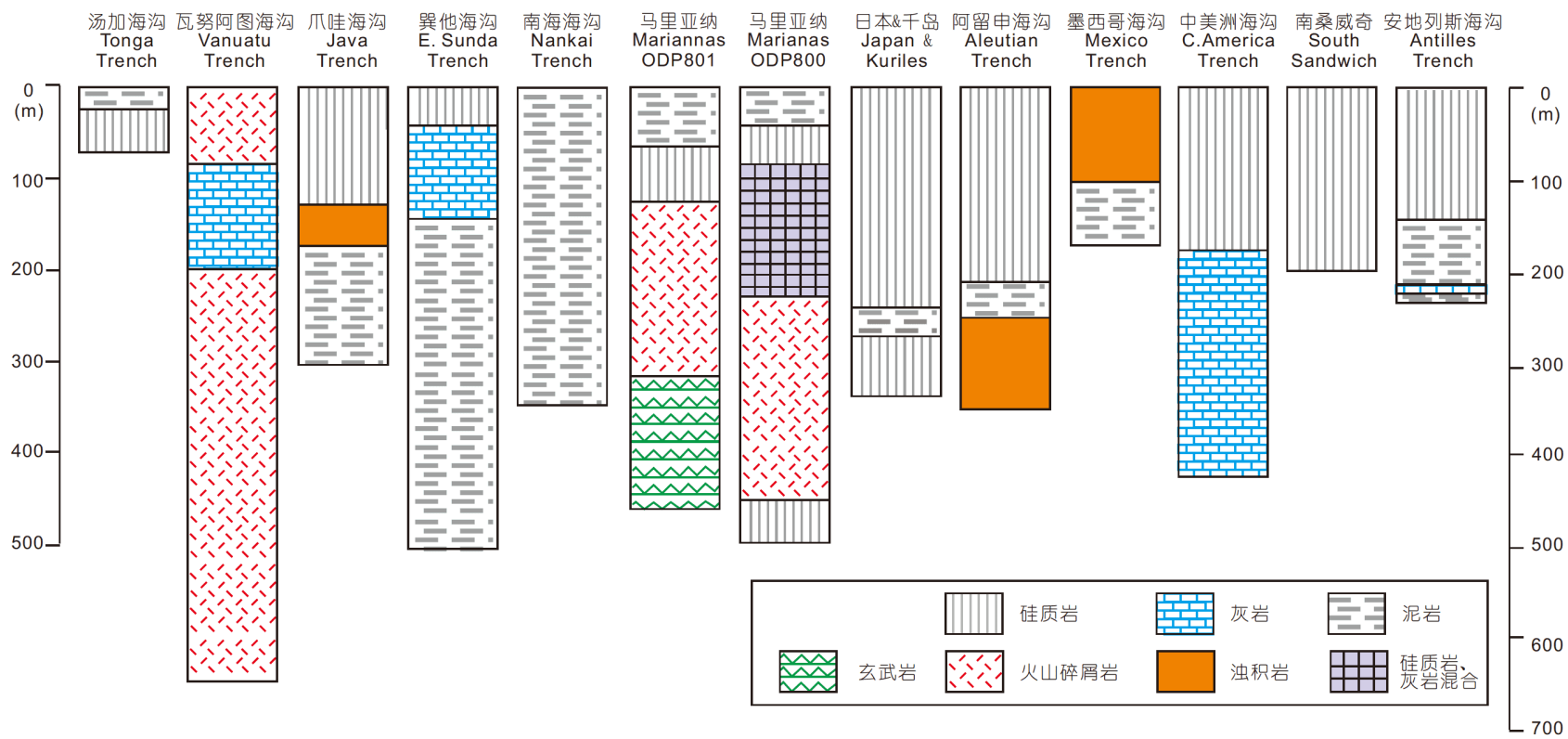

图 2 现代海沟盆地沉积物组成以及地层简图

修改自Plank和Langmuir(1998)

Plate Stratigraphy, OPS), 包括洋中脊玄武岩、远洋风 成泥质岩、硅质岩以及海山型玄武岩、灰岩等(Isozaki等, 1990; Wakita和Metcalfe, 2005); 另外一种为海沟 逐渐形成后通过沉降作用进入海沟的沉积物，包括陆 源、风成和宇宙源的黏土，火山灰、生物颗粒(包括浮 游生物钙质或硅质壳体)、海洋自生物质等. 通过国际 大洋钻探计划(DSDP、ODP和IODP)获取的沉积记录 与海沟盆地的汇聚速率计算获得的海沟沉积总量显 示, 陆源碎屑(黏土和砂岩)为 10.8 亿吨/年, 占总沉积物 通量的 $76 \%$ ，而碳酸钙、蛋白石年输入通量分别为 2.2
亿吨/年(占 $15 \%)$ 和 1.3 亿吨/年(占 $9 \%)(\mathrm{Rea}$ 和Ruff, 1996).

在大陆弧发育的增生造山带前缘，海沟盆地陆源 碎屑物质通常来自上覆板块陆壳和新生岩浆弧以及俯 冲杂岩(Kochelek等, 2011; An等, 2018). 盆地中碎屑颗 粒一般为中到粗砂岩, 砾岩也较常见, 成分以石英、酸 性火山岩碎屑为主. 来自俯冲杂岩的再沉积的碎屑则 一般为玄武岩、燧石、碳酸盐岩和泥岩，粒径可达砾 级. 海沟盆地内的沉积物并非都能保存下来. 在以构 造侵蚀为特征的俯冲带，没有任何增生作用，所有的 
海沟地层及从上覆板块铲刮下来的物质通过前端或底 部侵蚀的方式进入俯冲带深部(Noda，2016；Straub等， 2020). 在现代大洋俯冲带内, 沉积物的俯冲总量区别 很大: 全球来看, 现今长度约 $19 \%$ 的俯冲带内约 $30 \%$ 的 沉积物保留在表层, 没有进入俯冲通道, 因而发育较大 规模(大于 $40 \mathrm{~km}$ 宽)的俯冲增生杂岩; 约 $37 \%$ 的俯冲带 内约 $20 \%$ 的沉积物保留在表层, 没有进入俯冲通道, 仅 发育中小规模(5 40km宽)的俯冲增生杂岩; 剩下的约 44\%的俯冲带内沉积物全部进入俯冲通道，为侵蚀型， 俯冲增生杂岩不发育(von Huene和Scholl, 1991). 从地 域分布来看(表1)，东太平洋 $78.7 \%$ 俯冲带为增生型大 陆边缘，而西太平洋 $71 \%$ 俯冲带为侵蚀型大陆边缘 (von Huene和Scholl, 1991). Clift和Vannucchi(2004)进 一步研究表明, 东太平洋地区侵蚀型活动大陆边缘俯 冲带比以前认为的更普遍，达 $54.2 \%$, 包括了北智利、 秘鲁、墨西哥、厄瓜多尔-哥伦比亚等地区; 而西太平 洋侵蚀型的大陆边缘更是被严重低估了，达 $90 \%$ (Ranero和von Huene, 2000; Clift和Vannucchi, 2004). 相比 较而言, 印度洋、大西洋、地中海的俯冲带主要以增 生型为主(表1), 尤其是与喜马拉雅和安第斯山脉伴生 的造山带体系(Limonta等, 2015).

随着大洋板片俯冲的进行, 海沟盆地常被多次破 坏或强烈改造. 未进入俯冲通道的海沟沉积物, 被铲 刮堆积到海沟的向陆侧形成由构造岩片和混杂岩构成 的增生杂岩. 海沟沉积物在增生过程中通常会发生变
形和倒转，因此很难从中获取有效的古水流方向. 但 是，如果在一个构造岩片内，其内部构造变形不甚强 烈，内部组成和层序都得到良好保存，仍然可以运用 沉积学的基本原理来判别俯冲极性、沉积环境、沉积 过程、物源和源区的大地构造演化信息.

长期以来, 我们对海沟盆地的认识主要是基于对 现今大洋俯冲带海沟沉积的观察. 由于海沟盆地水体 极深, 很难进行大幅度的采样, 研究仅依赖地球物理 资料和少量的岩石学、沉积学和地层学信息(Kochelek等, 2011; Buchs等, 2015; 肖春晖等, 2017). 然而, 古 代的海沟盆地露头多位于造山带的轴部，经历了后期 强烈的构造变形. 在古老碰撞造山带中如何识别和研 究海沟盆地一直存在巨大的挑战, 很多科学问题也只 是浅尝轧止，缺乏深入的思考和研究. 本文系统介绍 了在喜马拉雅造山带-雅鲁藏布缝合带保存的大洋俯 冲阶段和大陆同碰撞时期海沟沉积的基本特征(产 状、沉积环境、物质组成、物质来源等). 通过对雅鲁 藏布缝合带藏南地区海沟盆地地层的野外观察和室内 分析, 提出了识别这类盆地的依据, 希望对其他造山带 海沟盆地的研究有所帮助.

\section{2 雅鲁藏布缝合带海沟盆地的发现}

雅鲁藏布缝合带经历了新特提斯洋壳向拉萨地体 的北向俯冲和随后的印度-亚洲大陆碰撞，由北向南依

表 1 现今大洋俯冲带增生型、侵蚀型板块边缘的长度与百分比

\begin{tabular}{|c|c|c|c|c|c|c|c|}
\hline \multirow{2}{*}{\multicolumn{2}{|c|}{ 海沟分布 }} & \multicolumn{3}{|c|}{ von Huene和Scholl(1991) } & \multicolumn{3}{|c|}{ Clift和Vannucchi(2004) } \\
\hline & & \multirow{2}{*}{$\frac{\text { 增生型 }}{24550}$} & \multirow{2}{*}{$\begin{array}{c}\text { 侵蚀型 } \\
18900\end{array}$} & \multirow{2}{*}{$\frac{\text { 总长度 }}{43450}$} & \multirow{2}{*}{$\frac{\text { 增生型 }}{17300}$} & \multirow{2}{*}{$\begin{array}{l}\text { 侵蚀型 } \\
22925\end{array}$} & \multirow{2}{*}{$\begin{array}{l}\text { 总长度 } \\
40225\end{array}$} \\
\hline 人球 & 海沟长度(km) & & & & & & \\
\hline 土场 & 百分比(\%) & 56.5 & 43.5 & - & 43.00 & 57.00 & - \\
\hline \multirow{2}{*}{ 太平洋 } & 海沟长度(km) & 17100 & 18100 & 35200 & 8550 & 22225 & 30775 \\
\hline & 百分比(\%) & 0.49 & 0.51 & - & 27.8 & 72.2 & - \\
\hline \multirow{2}{*}{ 东太平洋 } & 海沟长度(km) & 10900 & 2950 & 13850 & 6950 & 8225 & 15175 \\
\hline & 百分比(\%) & 78.7 & 21.3 & - & 45.8 & 54.2 & - \\
\hline \multirow{2}{*}{ 西太平洋 } & 海沟长度(km) & 6200 & 15150 & 21350 & 1600 & 14000 & 15600 \\
\hline & 百分比(\%) & 29.0 & 71.0 & - & 10.3 & 89.7 & - \\
\hline \multirow{2}{*}{ 印度洋 } & 海沟长度 $(\mathrm{km})$ & 5150 & 0 & 5150 & 6700 & 0 & 6700 \\
\hline & 百分比(\%) & 100 & 0 & - & 100 & 0 & - \\
\hline \multirow{2}{*}{ 大西洋-地中海 } & 海沟长度 $(\mathrm{km})$ & 2300 & 800 & 3100 & 2050 & 700 & 2750 \\
\hline & 百分比(\%) & 74.2 & 25.8 & - & 74.5 & 25.5 & - \\
\hline
\end{tabular}


次为冈底斯岩浆弧、日喀则弧前盆地、雅鲁藏布蛇绿 岩套和修康增生杂岩(An等(2018)称之为修康混杂岩, 图3), 记录了洋陆俯冲和陆陆碰撞的重要信息. 长期以 来, 地质学家对冈底斯岩浆弧、日喀则弧前盆地等单 元给予了极大的关注, 但是对更为复杂的缝合带的研 究相对较少. 由于藏南雅鲁藏布缝合带仅部分地区发 育小型的增生杂岩, 我们推测新特提斯洋主体为侵蚀 型活动大陆边缘(安慰，2015; Metcalf和Kapp，2019; Wei等, 2020). 近年来, 在雅鲁藏布缝合带中段先后成 功地识别出四套海沟沉积, 分别为东部江孜地区甲查
拉组、中部旦嘎地区荣马瓦组、西部萨嘎地区罗岗错 组和桑单林组-者雅组(图4). 另外, 在喜马拉雅西北部 的Indus缝合带, 也曾有类似的海沟沉积的报道(Garzanti和Van Haver, 1988).

甲查拉组出露于甲查拉山(江孜东部), 与宗卓组 呈断层接触(傅焓埔等, 2018). 甲查拉组总体表现为 中-薄层砂岩与页岩不等厚互层, 砂岩底面可见槽模构 造; 偶见小型的滑塌沉积, 黑色泥岩为基质, 夹有透镜 体状砂岩层和砂岩岩块(图 $5 \mathrm{a}$ 和 $5 \mathrm{~b}$ ), 沉积构造指示深 水海底扇朵体沉积环境(傅焓埔, 2020). 砂岩以岩屑石

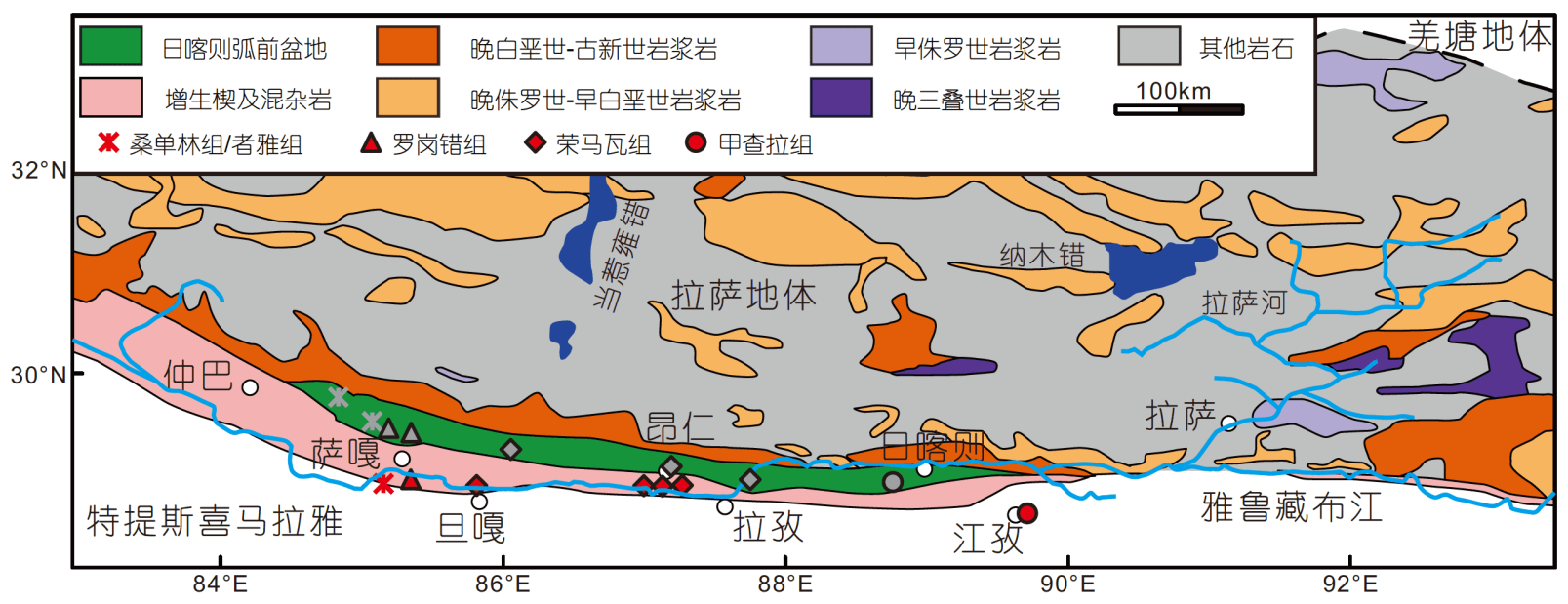

图 3 拉萨地体和雅鲁藏布缝合带地质简图

修改自Laskowski等(2019). 红色符号表示识别出来的海沟盆地剖面位置(Wang等, 2011; Cai等, 2012; DeCelles等, 2014; Wu等, 2014; Hu等, 2015; An等, 2018; Wang等, 2018; 傅焓埔等, 2018; Metcalf和Kapp, 2019; Laskowski等, 2019; Orme等, 2020), 灰色符号为做过物源分析的弧前盆 地剖面位置(图6和7; Wu等, 2010; An等, 2014; Orme等, 2014; Orme和Laskowski, 2016)

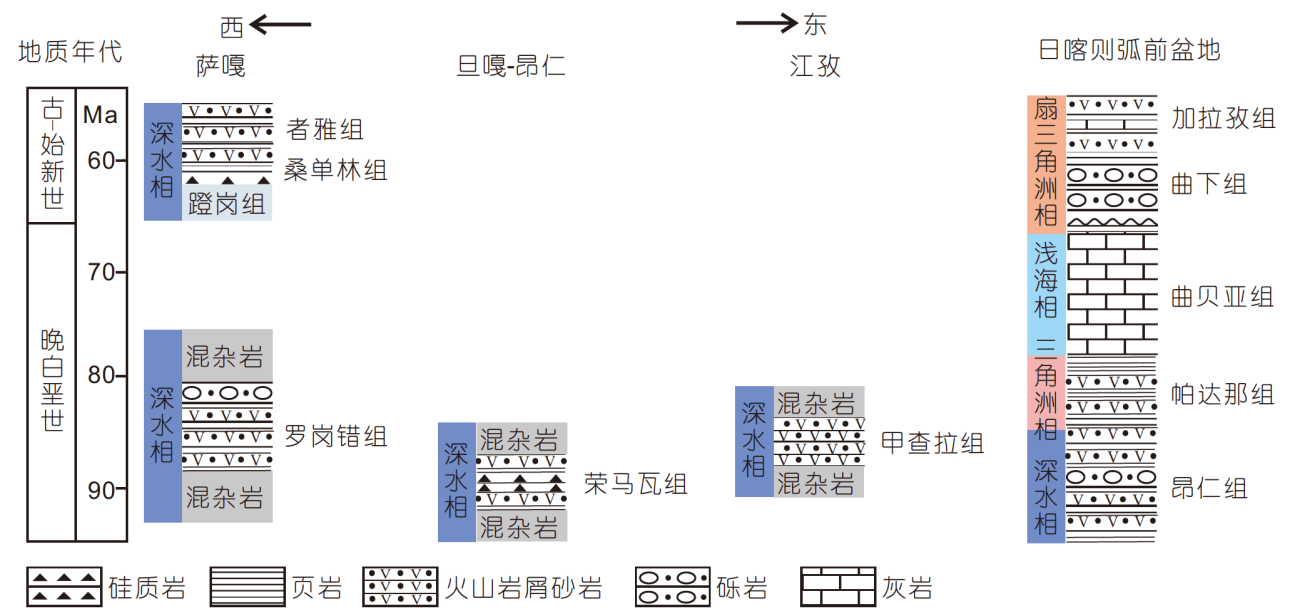

图 4 雅鲁藏布缝合带中部已识别的海沟地层柱状图及其与日喀则弧前盆地地层的对比 数据来源同图3 

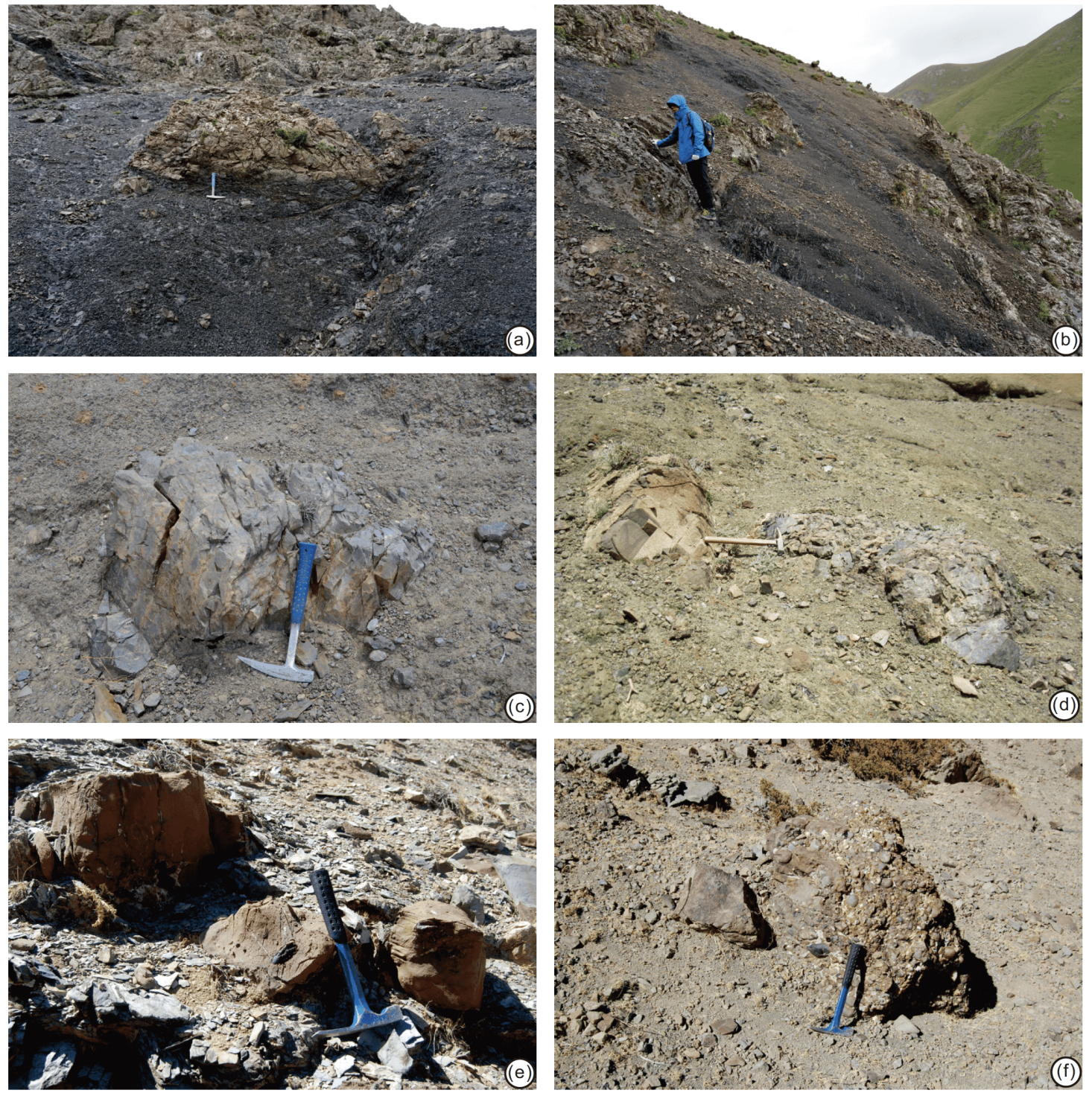

图 5 雅鲁藏布缝合带海沟盆地滑塌沉积中不同类型岩块的野外照片

(a)、(b) 砂岩岩块(甲查拉组); (c)、(d) 硅质岩岩块和砂岩岩块(罗岗错组); (e)、(f) 灰岩和砾岩岩块(者雅组)

英砂岩和长石石英砂岩为主, 岩屑多为火山岩岩屑(图 6)，依据碎屑锆石最年轻U-Pb年龄和区域对比大致推 断其沉积时代为晚白严世(约 $88 \sim 84 \mathrm{Ma}$; 傅焓埔等, 2018)(图7). 物源分析表明，甲查拉组碎屑物质来自冈 底斯岩浆弧和中拉萨地体，且晚三叠世-早侏罗世碎屑 锆石的出现指示海沟位置可能发育沿海沟的轴向搬运 (傅焓埔等, 2018).

中部昂仁-旦嘎地区的荣马瓦组与修康杂岩呈断 层接触(Cai等, 2012; Wang等, 2018; Orme等, 2020). 典 型剖面可分为上、中、下三段(Orme等, 2020), 上段和
下段为薄层砂岩与粉砂岩不等厚互层，砂岩中发育少 量生物扰动、平行层理和正粒序等沉积构造; 中段以 泥岩为主，夹少量硅质岩、薄层砂岩．沉积构造指示 该组上段和下段形成于海底扇远端沉积环境，中段为 浊流间歇期形成的泥岩. 砂岩多为长石石英砂岩和岩 屑石英砂岩(图6)，碎屑锆石最年轻U-Pb年龄指示其沉 积时代为晚白严世(约92 87Ma)(图7). 物源分析表明, 碎屑物质来自冈底斯岩浆弧和中拉萨地体. 由于晚三 叠世-早侏罗世的碎屑锆石的出现，Laskowski等(2019) 认为，碎屑物质通过古拉萨河的搬运越过冈底斯岩浆 

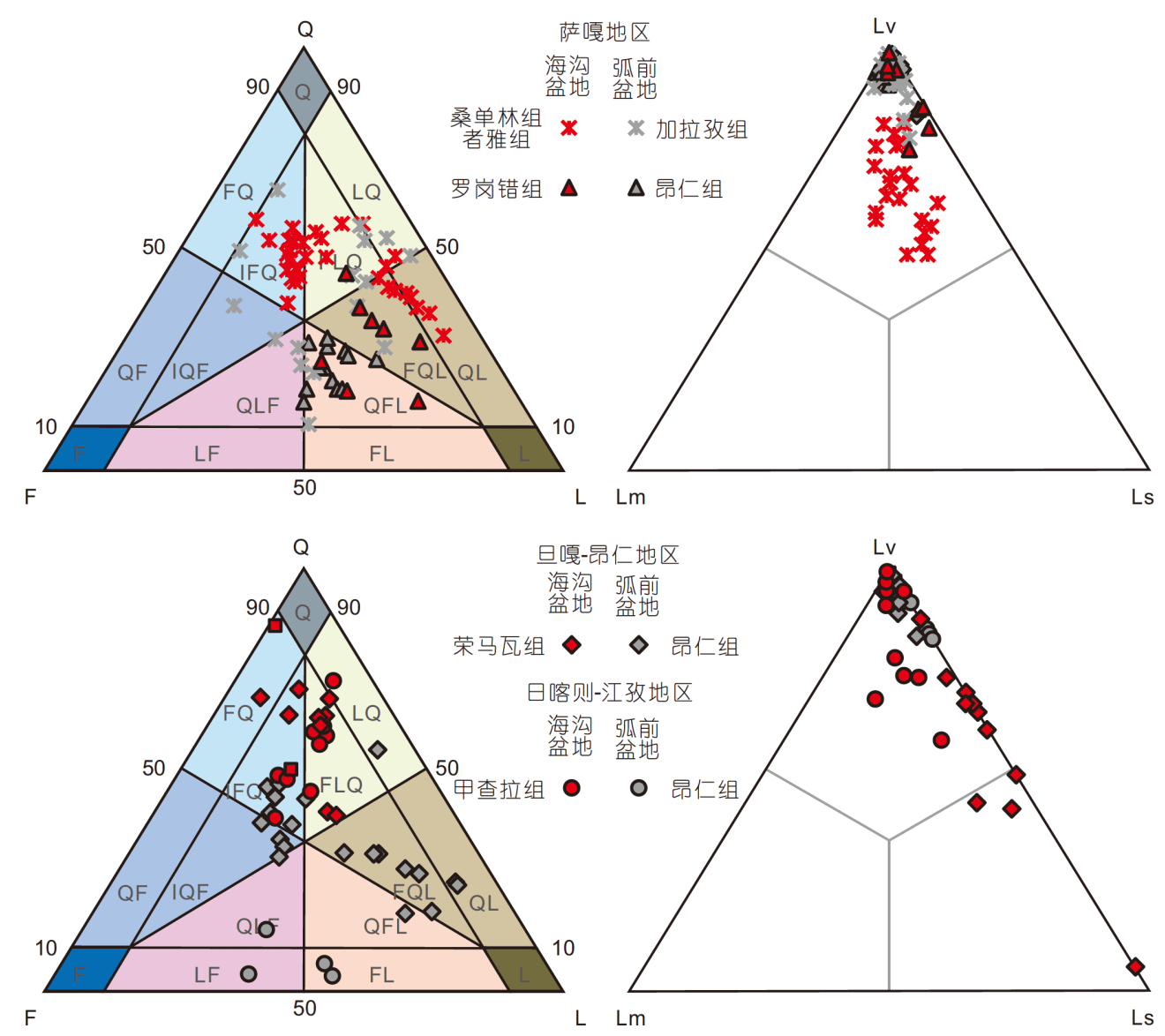

图 6 海沟盆地砂岩与对应的弧前盆地砂岩QFL、LvLmLs投图

Q, 石英; F, 长石; L, 岩屑; Lv, 火山岩岩屑; Lm, 变质岩岩屑; Ls, 沉积岩岩屑. 数据来源同图3, QFL底图和分类方案修改自Garzanti $(2016,2019)$

弧和日喀则弧前盆地到达新特提斯洋海沟, 并通过向 西的轴向搬运沉积至旦嘎海沟附近. 这一沉积物的搬 运方式与现今的日本富士河极为相似，富士河携带 Izu-Honshu碰撞带的碎屑物质切穿岩浆弧高地，注入 骏河(Suruga)峡谷, 经过 $400 \mathrm{~km}$ 长的深水水道的轴向 搬运，最终汇入Nankai海槽(e.g., Shimamura， 1989; Buchs等, 2015).

西部萨嘎地区罗岗错组与修康杂岩断层接触(图 8), 典型剖面上可见颗粒或基质支撑的砾岩及薄层砂 岩与泥岩不等厚互层. 砾岩层中的砾石多为棱角-次 棱角状，分选一般，可见滑塌成因的砂岩、灰岩等岩 块(图 $5 \mathrm{c}$ 和 $5 \mathrm{~d}$ )(An等，2018). 砂岩层中发育正粒序和 冲刷-充填等构造, 为海底扇远端沉积的浊积岩. 砂岩 以石英岩屑砂岩和长石岩屑砂岩为主(图6), 物源为 冈底斯岩浆弧和中拉萨地体. 而砾岩的砾石成分主要 为硅质岩, 指示其物源为修康增生杂岩, 主要通过垂
直于海沟的方向搬运. 碎屑锆石最年轻 $\mathrm{U}-\mathrm{Pb}$ 年龄指 示其沉积时代为晚白严世(约88 81Ma)(An等，2018) (图7).

萨嘎地区桑单林组-者雅组不整合沉积于印度被 动大陆北缘蹬岗组(图8), 之上浊积岩增多, 砂岩中同 沉积变形发育; 者雅组厚度大于 $500 \mathrm{~m}$, 以薄层砂岩与 页岩互层为主, 可见滑塌沉积, 含灰岩、砂岩等岩块 (图5e 5f)(Wang等, 2011; DeCelles等, 2014). 颗石藻和 放射虫的生物地层、凝灰岩锆石 $\mathrm{U}-\mathrm{Pb}$ 年龄等将沉积 时代精确约束为古新世中期((59 \pm 1$) \mathrm{Ma})(\mathrm{Hu}$ 等， 2015); 需要指出的是, 桑单林组早期浊积砂岩出现双向物源 的交互, 一个是来自印度大陆的纯石英砂岩; 另一个 是来自冈底斯岩浆弧和中拉萨地体的岩屑砂岩(Wang 等, 2011; DeCelles等, 2014). 至桑单林组上部和者雅组 沉积时期, 所有的浊积岩都由上覆的亚洲板块供给, 与 仲巴地区曲下组和加拉孜组一样, 物源来自紧邻北侧 

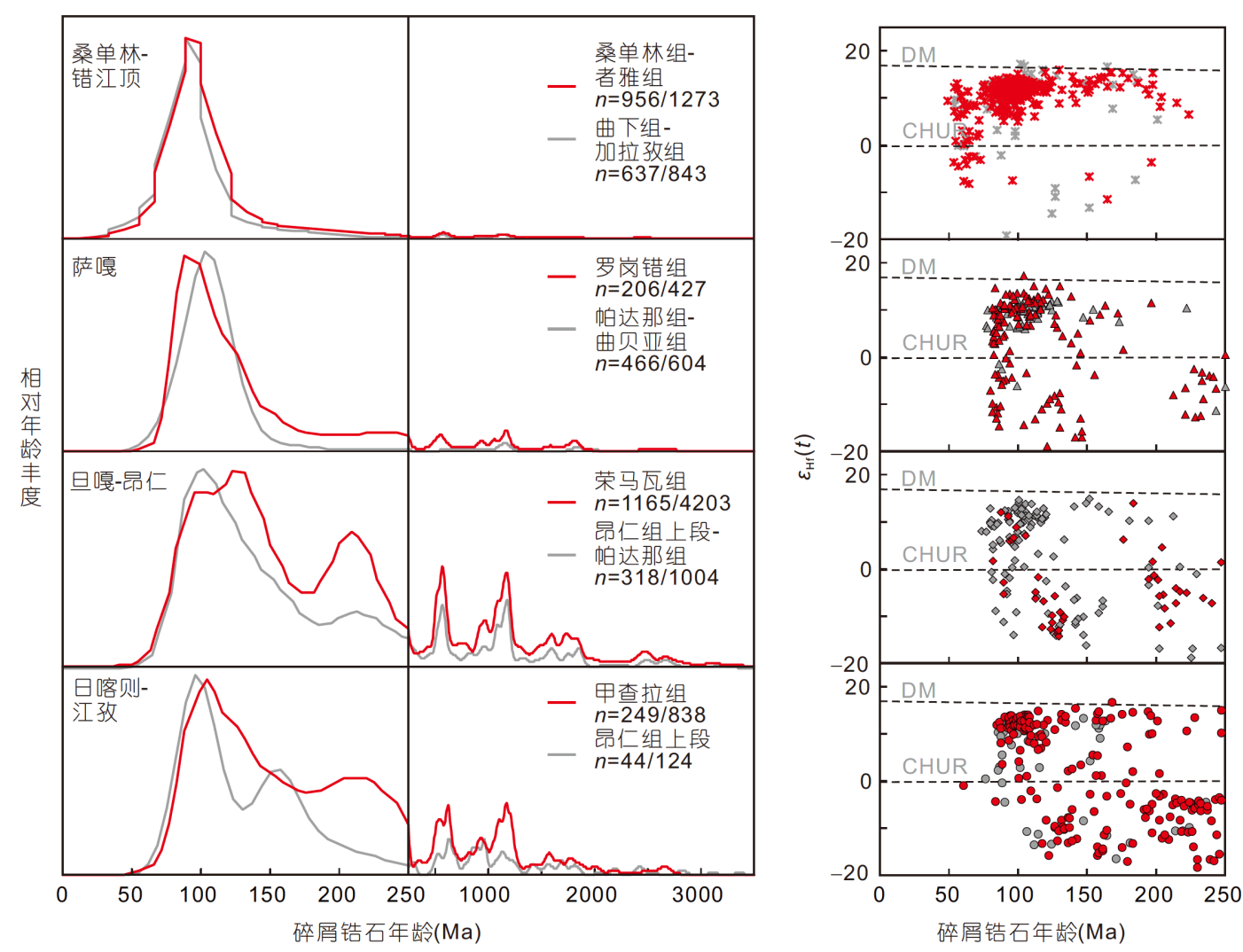

图 7 雅鲁藏布缝合带海沟盆地(红色)与对应时代的弧前盆地(灰色)砂岩碎屑锆石年龄组成 数据来源同图 3

的冈底斯岩浆弧和中拉萨(Wang等, 2011; DeCelles等, 2014; Wu等, 2014; Hu等, 2015, 2016).

根据地层的沉积时代和地球动力学背景，可以将 上述海沟地层分为两类: 甲查拉组、荣马瓦组、罗岗 错组为晚白严世新特提斯洋壳俯冲阶段的海沟沉积; 而古新世桑单林组和者雅组代表着同碰撞海沟盆地沉 积, 也即缝合带形成初期的海沟沉积 $(\mathrm{Hu}$ 等, 2015; 胡修 棉等, 2017). 需要指出的是, 也有学者认为桑单林组和 者雅组是周缘前陆盆地的前渊沉积(丁林，2003; DeCelles等, 2014, 2018). 事实上, 桑单林组-者雅组为初 始碰撞之前到同碰撞变形之间这一过渡期的沉积地 层, 之后被卷入喜马拉雅初期的冲断-褶皱带. 因此, 这 些地层单元并不能代表一套连续的前陆盆地沉积地层 的底部，而应该是在造山带大规模隆起和相应的前陆 盆地发育之前的最后一套海沟沉积. 与对应的日喀则 弧前盆地沉积物相比，甲查拉组、荣马瓦组砂岩更富 集石英和沉积岩岩屑(图6), 并包含更多三叠纪碎屑锆
石U-Pb年龄(约220 200Ma)(图7)。这就指示了存在额 外的晚三叠世岩浆岩源区 (或含有晚三叠世火山岩岩 屑的砂岩), 被推测来自冈底斯东部的拉萨地区附近 (现今的拉萨区域; Laskowski等, 2019). 而罗岗错组和 桑单林组-者雅组则与对应的弧前盆地沉积物基本一 致(图6和7), 推测二者具有相同的源区, 物源来自萨嘎仲巴地区的冈底斯弧的西侧(现今的萨嘎-仲巴地区; An等, 2018).

\section{3 与海沟盆地相邻的地质单元}

\section{1 特提斯喜马拉雅被动大陆边缘}

在萨嘎地区，海沟盆地及增生杂岩的南侧为侏罗 纪-白严纪深水沉积, 属于特提斯喜马拉雅构造单元 (图8). 特提斯喜马拉雅保存了印度被动大陆的经过构 造变形的残余地层(Sciunnach和Garzanti，2012): 南边 是一套奥陶纪-始新世的台地相碳酸盐岩和多种沉积 


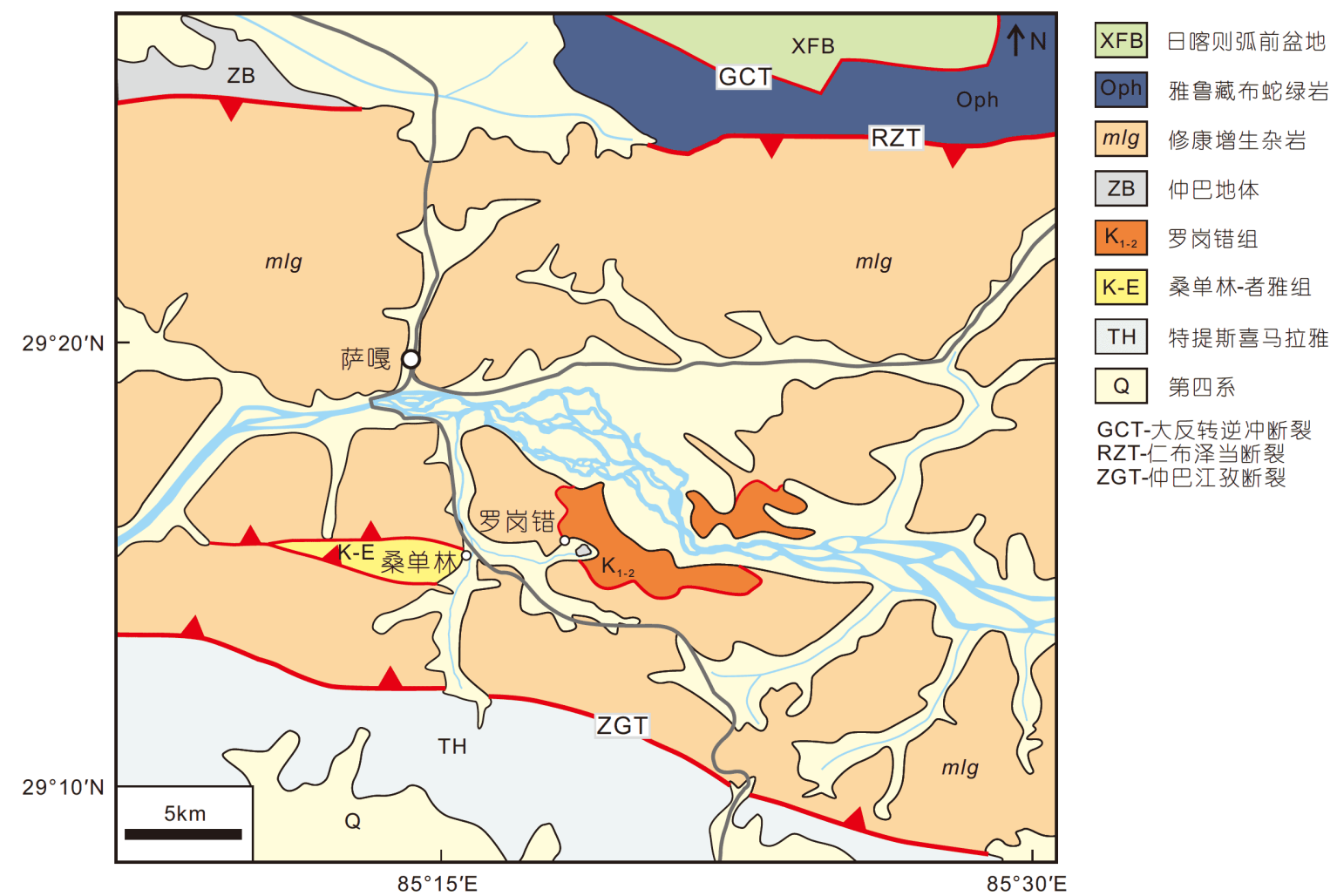

图 8 萨嘎地区地质简图, 指示罗岗错组、桑单林-者雅组海沟盆地的露头位置

桑单林-者雅组以构造岩片的形式出现在修康杂岩内, 紧邻南部的特提斯喜马拉雅被动大陆边缘地层. 修改自An等(2018)

环境下的陆源碎屑地层, 北边为一套中生代-始新世的 外陆棚、大陆坡和陆隆沉积(Jadoul等，1998; Hu等, 2008，2012). 在绝大部分地区，印度北缘被动大陆边 缘最顶部的地层被侵蚀削截，保存了大陆碰撞初期信 息的古近纪地层仅保存在藏南和喜马拉雅西北部的 Zanskar地区．而藏南地区更是目前为止唯一发现的保 存了原先沉积在洋壳-陆壳转换带上的沉积地层, 记录 了印度大陆首次抵达亚洲海沟的信息. 在萨嘎地区的 桑单林剖面, 印度-亚洲大陆初始碰撞之前的深水沉积 被称之为蹬岗组，它被认为沉积于大陆斜坡-盆地过渡 沉积环境，以硅质页岩夹薄-厚层浊积石英砂岩为特 征，物源来自沉积区南侧的印度大陆(Wang等，2011; $\mathrm{Hu}$ 等，2015; 胡修棉等，2017). 蹬岗组之上为桑单林 组, 代表被动大陆边缘的沉积结束, 出现印度来源的石 英砂岩和亚洲来源的岩屑砂岩交互沉积的现象 $(\mathrm{Hu}$ 等, 2015). 随后的者雅组为亚洲物源的同碰撞海沟盆地沉 积，这一时期由于构造抬升和变形终结了海沟盆地的 发育.

\section{2 修康俯冲杂岩}

在特提斯喜马拉雅被动大陆边缘地层和雅鲁藏布 蛇绿岩之间, 自仲巴-江孜一带连续出露一套以混杂岩 和变形强烈的构造岩片为特征的地质单元，被称之为 修康俯冲(或增生)杂岩(也有人称之为修康群、修康混 杂岩、羊卓雍错混杂岩等, 尹集祥和孙亦因, 1988; 安 尉, 2015; An等, 2017; Metcalf和Kapp, 2019). 该增生杂 岩带一部分表现出典型的岩块-基质的混杂构造, 其中 基质以泥岩、砂岩和硅质岩为主，岩块包括灰岩、砂 岩、基性岩、硅质岩岩块. 泥岩基质中含有晚白严世 Globotruncanas的化石，限定了该增生杂岩的最大形 成时代(常承法，1984). 近年来详细工作表明，修康增 生杂岩的物质来源复杂, 至少有三个来源: 一类为来自 印度大陆的浊积石英砂岩(Dupuis等, 2006), 第二类为 拉萨地体供给的晚白严世海沟盆地或海沟斜坡盆地浊 积岩屑砂岩(形成于印度-亚洲碰撞之前，Cai等，2012; $\mathrm{Li}$ 等, 2015; An等, 2017), 还有一类为来自新特提斯洋 

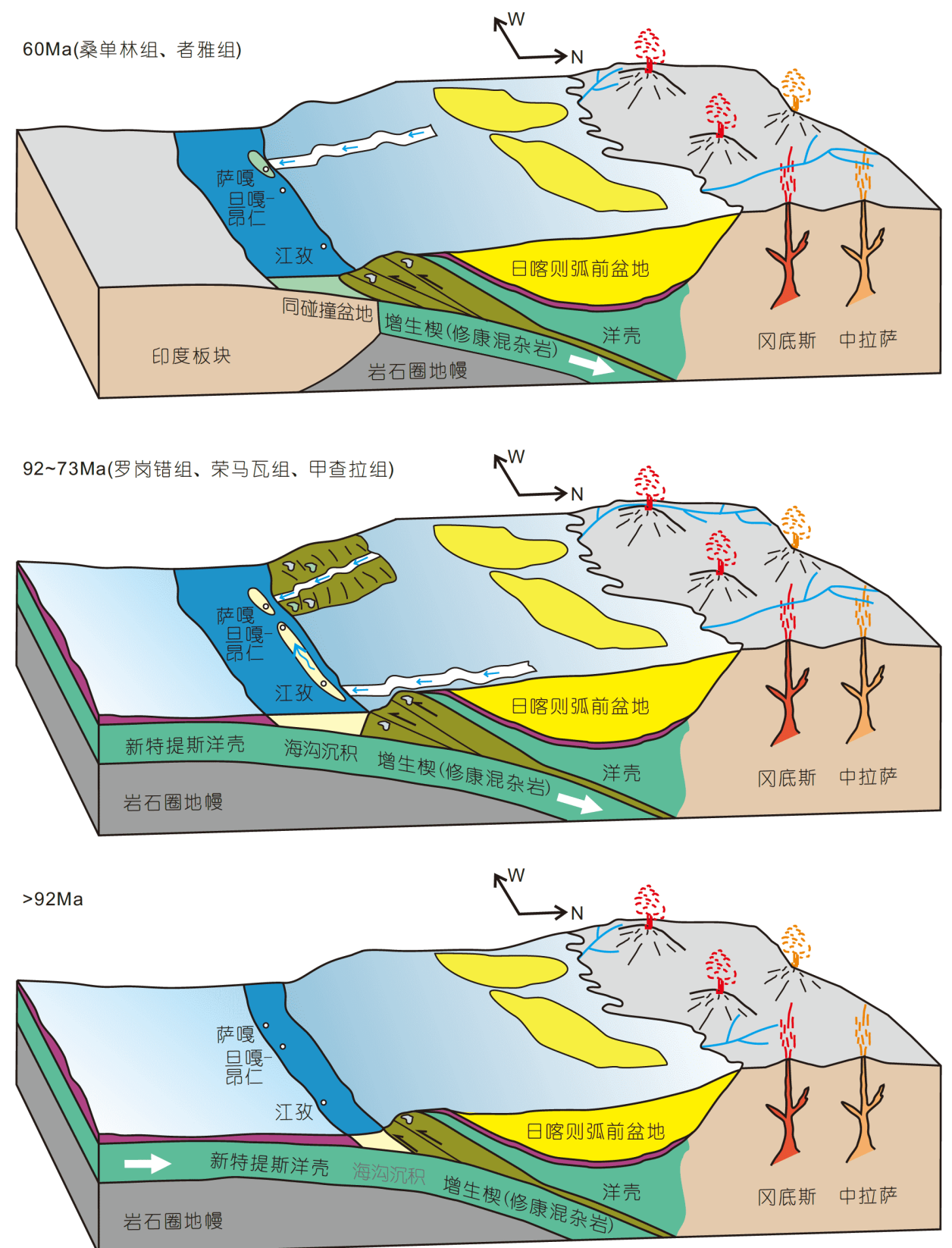

图 9 雅鲁藏布江缝合带晚白严世-古近纪海沟盆地演化示意图

下图: 晚白严世早期(>92Ma), 侵蚀型活动大陆边缘, 日喀则弧前盆地处于欠充填阶段, 海沟盆地不发育; 中图: 晚白严世中期(约92 73Ma), 部 分侵蚀性活动大陆边缘，日喀则弧前盆地基本充填，发育横向和纵向水系，海沟盆地以发育海底扇为主. 江孜-旦嘎地区接受东侧古拉萨河携 带的陆源碎屑, 形成甲查拉组和荣马瓦组; 萨嘎地区接受另一个水系的陆源供给, 形成罗岗错组; 上图: 古新世( 60Ma), 印度-亚洲大陆初始碰 撞阶段, 萨嘎地区桑单林组-者雅组保存了被卷入喜马拉雅逆冲断带之前最后的海沟沉积

的海山供给的玄武岩、灰岩(李文忠和沈树忠，2005; Dai等, 2012; An等, 2014). 传统观点认为, 修康杂岩作 为大洋俯冲阶段的增生杂岩发育于亚洲大陆南缘，其 形成时代应早于印度-亚洲大陆碰撞时间(Cai等,
2012). 然而，最新的野外工作及物源分析表明修康杂 岩是白严纪大洋俯冲阶段和古新世大陆碰撞两阶段共 同作用的结果(安慰，2015；An等，2017; Metcalf和 Kapp, 2017). 在印度-亚洲初始碰撞阶段, 被动大陆边 
缘深水沉积和海沟盆地沉积多以岩块的形式进入到修 康杂岩中, 仅少量以构造岩片的形式残存(图8).

\section{4 古地理演化}

综合分析日喀则弧前盆地、海沟盆地碎屑物质来 源后，可以勾勒拉萨地体晚白严世以来古地理和古水 系演化(图9). 早白严世时期，由于日喀则弧前盆地处 于欠充填阶段，碎屑物质被局限在弧前盆地，难以到 达海沟，该时期海沟盆地为饥饿状态；直到 92Ma，中 拉萨地体抬升(Lai等, 2019; Wang等, 2020)产生大量碎 屑沉积物, 使得日喀则弧前盆地快速充填, 此时碎屑物 质穿过弧前盆地和海沟斜坡到达海沟处形成甲查拉 组、荣马瓦组、罗岗错组. 有趣的是, 碎屑沉积物的低 温热年代学数据显示, 日喀则弧前盆地南缘在 $90 \mathrm{Ma}$ 出现一次快速冷却事件(Li等, 2017), 可能导致日喀则 弧前盆地的部分沉积物再旋回向南搬运进入海沟，这 与海沟盆地的砂岩相对富集石英和沉积岩岩屑是一致 的. 页岩、粉砂岩和砂岩岩屑中，石英颗粒磨圆较好， 且多具有磨蚀的次生加大边, 反映了沉积物质广泛再 循环的过程. 同样的情况也出现在喜马拉雅西北部Indus缝合带混杂岩单元的砂岩(Garzanti和Van Haver, 1988). 古新世中期印度亚洲大陆初始碰撞引发的构造 事件，导致了海沟盆地沉积物的快速充填. 江孜-旦嘎 地区与萨嘎地区的海沟盆地具有不同的沉积物搬运途 径, 分别以横向搬运和纵向搬运为主, 这一区别可能受 控于晚白严世新特提斯洋海沟盆地底部的地形差异、 碎屑物质的注入位置以及沉积物供给量等因素.

\section{5 海沟盆地的特征与识别依据}

海沟盆地位于大洋俯冲带，通常具有以下特征: (1) 水深通常位于 $\mathrm{CCD}$ 面之下，以广泛发育硅质和黏 土质沉积为主，普遍缺乏钻质沉积；(2) 构造不稳定， 因此重力流沉积广为发育, 包括浊流沉积、碎屑流沉 积和滑塌沉积；(3) 搬运的碎屑物质主要来自上覆板 块, 包括火山弧、弧后区域, 以及俯冲杂岩; 古水流方 向可以垂直海沟，也可以平行海沟; (4) 垂向上呈现粒 度向上变粗的趋势, 从硅质岩、黏土岩为主, 过渡为以 浊积砂岩为主; (5) 地理分布上, 海沟盆地平行于缝合 带并且呈线状或弧形分布; (6) 构造变形强烈, 与大洋
俯冲带增生楔形成和随后的大陆碰撞过程有关.

鉴于缝合带构造演化的复杂性，在造山带中识别 海沟盆地困难重重. 一个陆源碎屑供给充足的、成熟 的增生型“沟-弧”体系是海沟盆地形成和保存的必要 条件. 然而, 并非所有的海沟盆地都能满足这样的条 件. 在构造侵蚀型的活动大陆边缘, 譬如现今太平洋 的西侧以及东侧的大部分(Clift和Vannucchi, 2004), 海 沟盆地形成后被迅速破坏, 绝大部分的沉积物被俯冲 殆尽, 保存的可能性极小. 因此, 并非所有造山带内部 的缝合带都有可以识别的俯冲体系和海沟盆地沉积.

由于具有相似的沉积时代和物质组成(物源和成 分特征), 海沟盆地与同期的弧前盆地一般很难区分. 近年来雅鲁藏布缝合带内的海沟盆地的详细研究 (An 等, 2017, 2018; 傅焓埔等, 2018; Orme等, 2020)为在造 山带识别海沟盆地沉积地层、并有效区分海沟盆地充 填与弧前盆地沉积地层提供了一些借鉴. 海沟盆地与 弧前盆地的有效识别依据可以归纳为以下几点：(1) 大地构造位置上, 海沟盆地位于蛇绿杂岩(一般代表弧 前盆地的基底)和下伏板块的被动大陆边缘沉积之间， 而弧前盆地常位于蛇绿杂岩与大陆弧之间(图8); (2) 沉积过程方面, 相比较弧前盆地而言, 海沟盆地的地 层以远洋-半远洋沉积物为背景, 出现规模不等的浊积 岩、滑塌和碎屑流沉积等; (3) 沉积环境方面, 通常为 $\mathrm{CCD}$ 面之下的深水环境, 钙质沉积少, 缺少弧前盆地晚 期的陆棚、浅海环境; (4) 沉积结构单元方面, 海沟盆 地浊流沉积多为海底扇朵体环境, 而弧前盆地主要广 泛发育水道-天然堤沉积; (5) 搬运方式和物质组成方 面, 海沟内部轴向水道发育, 且与大陆边缘大型河流水 系连通, 因而其物质来源比弧前盆地更复杂, 碎屑组成 相较于弧前盆地更富集稳定组分(如石英等), 反映了 俯冲杂岩或弧前盆地沉积物质的广泛再循环过程.

在增生型大陆边缘, 海沟盆地沉积常以构造岩片 的方式保存在俯冲杂岩内, 为俯冲杂岩的重要组成部 分. 在俯冲杂岩之上, 也可发育一些沉积盆地, 通常可 见于现代体系的地震剖面(Underwood和Moore，1995; Lackey等，2020). 这些盆地的底界由于后期构造破坏 一般发生强烈变形，这导致了在造山带中进一步区分 海沟斜坡盆地、楔顶盆地、海沟盆地的困难. 造山带 海沟盆地的有效识别是理解大洋俯冲和陆陆碰撞过程 的首要步骤. 可以预期, 随着研究程度的不断提高, 在 其他碰撞造山带中成功识别海沟盆地的案例将会越来 
越多. 本文基于雅鲁藏布缝合带首次总结了造山带海 沟盆地的基本特征和识别依据，对于进一步验证与完 善世界上其他造山带沉积过程研究具有借鉴意义.

致谢 衰心感谢郑永飞、吴福元、王成善、Devon Orme、 李广伟、王建刚、孙高远、赖文、薛伟伟、梁文栋提出 的意见和帮助。同时也感谢两位若名评审专家的建设性 意见.

\section{参考文献}

安慰. 2015. 西藏日喀则地区新特提斯洋俯冲体系沉积记录与盆地 演化. 博士学位论文. 南京: 南京大学. 101

常承法. 1984. 雅鲁藏布江缝合带地质构造特征及演化. 中法喜马拉 雅考察成果. 北京: 地质出版社. 327-340

丁林. 2003. 西藏雅鲁藏布江缝合带古新世深水沉积和放射虫动物 群的发现及对前陆盆地演化的制约. 中国科学 $\mathrm{D}$ 辑: 地球科学, 33: $47-58$

傅焓埔, 胡修棉, Crouch E M, 安慰, 王建刚, Garzanti E. 2018. 西藏雅 鲁藏布缝合带甲查拉组: 晚白严世新特提斯洋海沟沉积? 中国科 学: 地球科学, 48: 1275-1292

傅焓埔. 2020. 西藏雅鲁藏布缝合带甲查拉组海沟沉积. 博士学位论 文. 南京: 南京大学. 126

河北区域地质调查院. 2002. 1:25万萨嘎县幅(H45C003001)区域地质 调查报告

胡修棉, 王建刚, 安慰, Garzanti E, 李娟. 2017. 利用沉积记录精确约 束印度-亚洲大陆碰撞时间与过程. 中国科学: 地球科学, 47: 261283

李文忠, 沈树忠. 2005. 西藏雅鲁藏布江缝合带二叠纪灰岩体的动物 群及其古地理意义. 地质论评, 51: 225-233

肖春晖, 王永红, 林间. 2017. 海沟沉积物研究进展. 热带海洋学报, 36: $27-38$

尹集祥, 孙亦因. 1988. 西藏南部拉孜县中贝地区的三叠系. 中国科 学院地质研究所集刊, 3: 73-79

An W, Hu X M, Garzanti E, BouDagher-Fadel M K, Wang J G, Sun G Y. 2014. Xigaze forearc basin revisited (South Tibet): Provenance changes and origin of the Xigaze Ophiolite. Geol Soc Am Bull, 126: $1595-1613$

An W, Hu X M, Garzanti E. 2017. Sandstone provenance and tectonic evolution of the Xiukang Mélange from Neotethyan subduction to India-Asia collision (Yarlung-Zangbo suture, south Tibet). Gondwana Res, 41: 222-234

An W, Hu X M, Garzanti E. 2018. Discovery of Upper Cretaceous NeoTethyan trench deposits in south Tibet (Luogangcuo Formation).
Lithosphere, 10: 446-459

Buchs D M, Cukur D, Masago H, Garbe-Schönberg D. 2015. Sediment flow routing during formation of forearc basins: Constraints from integrated analysis of detrital pyroxenes and stratigraphy in the Kumano Basin, Japan. Earth Planet Sci Lett, 414: 164-175

Cai F, Ding L, Leary R J, Wang H, Xu Q, Zhang L, Yue Y. 2012. Tectonostratigraphy and provenance of an accretionary complex within the Yarlung-Zangpo suture zone, southern Tibet: Insights into subduction-accretion processes in the Neo-Tethys. Tectonophysics, 574-575: 181-192

Clift P, Vannucchi P. 2004. Controls on tectonic accretion versus erosion in subduction zones: Implications for the origin and recycling of the continental crust. Rev Geophys, 42: RG2001

Dai J G, Wang C S, Li Y L. 2012. Relicts of the Early Cretaceous seamounts in the central-western Yarlung Zangbo Suture Zone, southern Tibet. J Asian Earth Sci, 53: 25-37

DeCelles P G, Kapp P, Gehrels G E, Ding L. 2014. Paleocene-Eocene foreland basin evolution in the Himalaya of southern Tibet and Nepal: Implications for the age of initial India-Asia collision. Tectonics, 33: 824-849

DeCelles P G, Leary R J, Kapp P. 2018. Cenozoic basin evolution in the Indus-Yarlung suture zone and High Himalaya. In: Ingersoll R V, Lawton T F, Graham S A, eds. Tectonics, Sedimentary Basins, and Provenance: A Celebration of William R. Dickinson's Career. Geol Soc Am Bull Special Paper, 540: 707-739

Dickinson W R. 1995. Forearc basins. In: Busby C J, Ingersoll R V, ed. Tectonics of Sedimentary Basins. Cambridge, Massachusetts: Blackwell Science. 221-261

Dupuis C, Hébert R, Dubois-Côté V, Guilmette C, Wang C S, Li Z J. 2006. Geochemistry of sedimentary rocks from mélange and flysch units south of the Yarlung Zangbo suture zone, southern Tibet. J Asian Earth Sci, 26: 489-508

Garzanti E. 2016. From static to dynamic provenance analysisSedimentary petrology upgraded. Sediment Geol, 336: 3-13

Garzanti E. 2019. Petrographic classification of sand and sandstone. Earth-Sci Rev, 192: 545-563

Garzanti E, Van Haver T. 1988. The Indus clastics: Forearc basin sedimentation in the Ladakh Himalaya (India). Sediment Geol, 59: $237-249$

Hu X M, Jansa L, Wang C S. 2008. Upper Jurassic-Lower Cretaceous stratigraphy in south-eastern Tibet: A comparison with the western Himalayas. Cretac Res, 29: 301-315

Hu X M, Sinclair H D, Wang J G, Jiang H H, Wu F Y. 2012. Late Cretaceous-Palaeogene stratigraphic and basin evolution in the Zhepure Mountain of southern Tibet: Implications for the timing of India-Asia initial collision. Basin Res, 24: 520-543 
Hu X M, Garzanti E, Moore T, Raffi I. 2015. Direct stratigraphic dating of India-Asia collision onset at the Selandian (middle Paleocene, 59 $\pm 1 \mathrm{Ma})$. Geology, 43: 859-862

Hu X M, Wang J G, BouDagher-Fadel M, Garzanti E, An W. 2016. New insights into the timing of the India-Asia collision from the Paleogene Quxia and Jialazi formations of the Xigaze forearc basin, South Tibet. Gondwana Res, 32: 76-92

Isozaki Y, Maruyama S, Furuoka F. 1990. Accreted oceanic materials in Japan. Tectonophysics, 181: 179-205

Jadoul F, Berra F, Garzanti E. 1998. The Tethys Himalayan passive margin from late Triassic to early Cretaceous (South Tibet). J Asian Earth Sci, 16: 173-194

Kochelek E J, Amato J M, Pavlis T L, Clift P D. 2011. Flysch deposition and preservation of coherent bedding in an accretionary complex: Detrital zircon ages from the Upper Cretaceous Valdez Group, Chugach terrane, Alaska. Lithosphere, 3: 265-274

Lackey J K, Regalla C A, Moore G F. 2020. Tectonic influences on trench slope basin development via structural restoration along the outer Nankai accretionary prism, southwest Japan. Geochem Geophys Geosyst, 21: e09038

Laskowski A K, Orme D A, Cai F, Ding L. 2019. The Ancestral Lhasa River: A Late Cretaceous trans-arc river that drained the protoTibetan Plateau. Geology, 47: 1029-1033

Lai W, Hu X M, Garzanti E, Sun G Y, Garzione C N, BouDagher-Fadel M, Ma A L. 2019. Initial growth of the Northern Lhasaplano (Tibetan Plateau) in the early Late Cretaceous (92 Ma). Geol Soc Am Bull, 131: 1823-1836

Li G W, Sandiford M, Boger S, Liu X, Wei L. 2015. Provenance of the Upper Cretaceous to Lower Tertiary sedimentary relicts in the Renbu Mélange Zone, within the Indus-Yarlung Suture Zone. J Geol, 123: 39-54

Li G W, Kohn B, Sandiford M, Xu Z Q. 2017. India-Asia convergence: Insights from burial and exhumation of the Xigaze fore-arc basin, south Tibet. J Geophys Res-Solid Earth, 122: 3430-3449

Limonta M, Garzanti E, Resentini A, Andò S, Boni M, Bechstädt T. 2015. Multicyclic sediment transfer along and across convergent plate boundaries (Barbados, Lesser Antilles). Basin Res, 27: 696713

Metcalf K, Kapp P. 2017. The Yarlung suture mélange, Lopu Range, southern Tibet: Provenance of sandstone blocks and transition from oceanic subduction to continental collision. Gondwana Res, 48: 1533

Metcalf K, Kapp P. 2019. History of subduction erosion and accretion recorded in the Yarlung Suture Zone, southern Tibet. Geol Soc Lond Spec Publ, 483: 517-554

Noda A. 2016. Forearc basins: Types, geometries, and relationships to subduction zone dynamics. Geol Soc Am Bull, 128: 879-895

Orme D A, Carrapa B, Kapp P. 2014. Sedimentology, provenance and geochronology of the upper Cretaceous-lower Eocene western Xigaze forearc basin, southern Tibet. Basin Res, 27: 387-411

Orme D A, Laskowski A K. 2016. Basin analysis of the AlbianSantonian Xigaze forearc, Lazi region, south-central Tibet. J Sedimentary Res, 86: 894-913

Orme D A, Laskowski A K, Zilinsky M F, Chao W, Guo X, Cai F, Lin D. 2020. Sedimentology and provenance of newly identified Upper Cretaceous trench basin strata, Dênggar, southern Tibet: Implications for development of the Eurasian margin prior to India-Asia collision. Basin Res, doi: 10.1111/bre.12521

Plank T, Langmuir C H. 1998. The chemical composition of subducting sediment and its consequences for the crust and mantle. Chem Geol, 145: $325-394$

Rea D K, Ruff L J. 1996. Composition and mass flux of sediment entering the world's subduction zones: Implications for global sediment budgets, great earthquakes, and volcanism. Earth Planet Sci Lett, 140: 1-12

Ranero C R, von Huene R. 2000. Subduction erosion along the Middle America convergent margin. Nature, 404: 748-752

Sciunnach D, Garzanti E. 2012. Subsidence history of the Tethys Himalaya. Earth-Sci Rev, 111: 179-198

Shimamura K. 1989. Topography and sedimentary facies of the Nankai deep sea channel. In: Taira A, Masuda F, eds. Sedimentary Facies in the Active Plate Margin. Tokyo: Terra Scientific Publishing Company. 529-556

Straub S M, Gómez-Tuena A, Vannucchi P. 2020. Subduction erosion and arc volcanism. Nat Rev Earth Environ, doi: 10.1038/s43017020-0095-1

Thornburg T M, Kulm L D. 1987. Sedimentation in the Chile Trench: Depositional morphologies, lithofacies, and stratigraphy. Geol Soc Am Bull, 98: 33-52

Underwood M, Moore G. 1995. Trenches and Trench-slope basins. In: Busby C J, Ingersoll R V, ed. Tectonics of Sedimentary Basins. Cambridge, Massachusetts: Blackwell Science. 179-219

Underwood M B, Moore G F. 2011. Evolution of sedimentary environments in the subduction zone of southwest Japan: Recent results from the NanTroSEIZE Kumano Transect. In: Busby C J, Antonio A, eds. Tectonics of Sedimentary Basins: Recent Advances. Blackwell: John Wiley \& Sons, Ltd. 310-328

von Huene R, Scholl D W. 1991. Observations at convergent margins concerning sediment subduction, subduction erosion, and the growth of continental crust. Rev Geophys, 29: 279-316

Wakita K, Metcalfe I. 2005. Ocean plate stratigraphy in East and Southeast Asia. J Asian Earth Sci, 24: 679-702 
Wang J, Hu X, Jansa L, Huang Z. 2011. Provenance of the Upper Cretaceous-Eocene deep-water sandstones in Sangdanlin, southern Tibet: Constraints on the timing of initial India-Asia collision. J Geol, 119: 293-309

Wang H Q, Ding L, Kapp P, Cai F L, Clinkscales C, Xu Q, Yue Y H, Li S, Fan S Q. 2018. Earliest Cretaceous accretion of Neo-Tethys oceanic subduction along the Yarlung Zangbo suture zone, Sangsang area, southern Tibet. Tectonophysics, 744: 373-389

Wang J G, Hu X, Garzanti E, BouDagher-Fadel M K, Liu Z C, Li J, Wu F Y. 2020. From extension to tectonic inversion: Mid-Cretaceous onset of Andean-type orogeny in the Lhasa block and early topographic growth of Tibet. Geol Soc Am Bull, doi: 10.1130/
B35314

Wei Z, Li X H, Li Y X, Fan X L, Wang J Y, Zhang C K, Jiebu G J. 2020. Discovery of vestige sedimentary archives of the India-Asia collision in the Eastern Yarlung Zangbo Suture Zone. J Geophys Res-Solid Earth, 125: e18192

Wu F Y, Ji W Q, Liu C Z, Chung S L. 2010. Detrital zircon U-Pb and Hf isotopic data from the Xigaze fore-arc basin: Constraints on Transhimalayan magmatic evolution in southern Tibet. Chem Geol, 271: 13-25

Wu F Y, Ji W Q, Wang J G, Liu C Z, Chung S L, Clift P D. 2014. Zircon $\mathrm{U}-\mathrm{Pb}$ and $\mathrm{Hf}$ isotopic constraints on the onset time of IndiaAsia collision. Am J Sci, 314: 548-579

(责任编委: 郑永飞) 